REVESCO. Revista de Estudios Cooperativos

ISSN: $1885-8031$

\title{
La transparencia de las formaciones políticas españolas: un estudio empírico
}

\author{
Juan Antonio Meca Valles ${ }^{1}$, Isidoro Guzmán Raja ${ }^{2}$ y Manuela Guzmán Raja ${ }^{3}$
}

Recibido: 25 de agosto de 2020 / Aceptado: 20 de enero de 2021 / Publicado: 19 de abril de 2021

Resumen. La Ley 19/2013 de transparencia, acceso a la información pública y buen gobierno tiene como objetivo primordial la puesta en práctica del derecho de acceso de los ciudadanos a la información, para conocer los criterios bajo los que se adoptan las decisiones dirigidas a la aplicación de los recursos públicos, de manera que la ciudadanía pueda fiscalizar de forma directa la actuación de los organismos públicos y privados que quedan bajo el ámbito de la legislación citada, al que también pertenecen los partidos políticos.

En el contexto descrito, el objetivo del presente trabajo es evaluar el nivel de transparencia alcanzado por las formaciones políticas en España, a través de la información que facilitan en sus respectivas páginas web oficiales. A tal efecto, se diseñaron sendos índices de transparencia desde la perspectiva organizativa y económica sobre una muestra de partidos políticos con representación parlamentaria desde la instauración de la democracia en España, con el fin de conocer sus puntuaciones de transparencia, así como la relación entre ambos índices a través de la aplicación de un modelo econométrico.

Los resultados revelan un escaso nivel de transparencia de la mayoría de las formaciones políticas analizadas, tanto en el ámbito organizativo como económico, detectándose una relación positiva entre los índices de transparencia organizativa y económica, especialmente influenciada por la funcionalidad de las páginas web de dichos entes.

Palabras clave: Partidos políticos; Transparencia; Acceso información pública; Índices de transparencia; Información en páginas web.

Claves Econlit: D64; H83; L30.

\section{[en] The transparency of spanish political formations: an empirical study}

\begin{abstract}
The main objective of Law 19/2013 on transparency, access to public information and good governance is to put into practice the right of citizens to access information in order to know the criteria under which decisions aimed at the application of public resources are taken, so that citizens can directly control the actions of public and private bodies, which fall under the scope of the aforementioned legislation, to which political parties also belong.

In the context described, the aim of this paper is to evaluate the level of transparency achieved by political parties in Spain, through the information they provide on their respective official websites. To this end, two transparency indices were designed from an organisational and economic perspective on a sample of political parties with parliamentary representation since the establishment of democracy in Spain, in order to find out their transparency scores, as well as the relationship between both indices through the application of an econometric model.

The results reveal a low level of transparency in most of the political groups analysed, both in the organisational and economic spheres, and a positive relationship was detected between the organisational and economic transparency indexes, especially influenced by the functionality of the websites of these entities.
\end{abstract}

Keywords: Political parties; Transparency; Access public information; Transparency indexes; Information on web pages.

Sumario. 1. Introducción. 2. El concepto de transparencia y su de desarrollo: publicidad activa y buen gobierno. 3. Materiales y métodos. 4. Conclusiones. 5. Referencias bibliográficas.

Cómo citar. Meca Valles, J.A.; Guzmán Raja, I.; Guzmán Raja, M. (2021) La transparencia de las formaciones políticas españolas: un estudio empírico. REVESCO. Revista de Estudios Cooperativos, vol. 138, e73871. https://dx.doi.org/10.5209/reve.73871.

1 Universidad Politécnica de Cartagena, España.

Dirección de correo electrónico: jmecavalles@gmail.com.

2 Universidad Politécnica de Cartagena, España.

Dirección de correo electrónico: isidoro.guzman@upct.es.

3 Universidad Politécnica de Cartagena, España.

Dirección de correo electrónico: manoli.guzman@upct.es. 


\section{Introducción}

La transparencia hace referencia a toda actuación pública que muestra, sin ánimo de omitir información, la realidad de los hechos (Oxford University Press, 2020), y se configura como fundamental en un Estado de derecho, pudiendo analizarse desde diferentes perspectivas, tales como la económica, la social, o la medioambiental etc., y ser alcanzada a través de distintos medios, como, por ejemplo, telemáticos o por la vía de las auditorías.

En el año 2013 se publicó en España la Ley 19/2013, de 9 de diciembre, de transparencia, acceso a la información pública y buen gobierno (en adelante, Ley de Transparencia), en cuyo preámbulo se señala que "la experiencia demuestra que aquellos países los cuales disponen de mayores niveles de transparencia y buen gobierno tienen unas instituciones más consolidadas, lo que favorece la cohesión y el desarrollo social, debido a que los ciudadanos disponen de más información para poder valorar con criterio cual es la capacidad de sus responsables públicos y decidir en consecuencia". En este sentido, la transparencia de las entidades públicas (y políticas) adquiere un papel más vertebrador si cabe para el caso de España, puesto que las últimas décadas han estado marcadas por continuos episodios que han hecho que de alguna manera se tambalee su propia credibilidad junto con la de sus líderes.

Con respecto a las formaciones políticas, la legislación que regula directamente sus actividades se encuentra recogida fundamentalmente en la Ley Orgánica 6/2002, de 27 de junio, de partidos políticos, junto con la Ley Orgánica 8/2007, de 4 de julio, sobre financiación de los partidos políticos (reformada por la Ley Orgánica 5/2012 de 22 de octubre) y la Ley Orgánica 3/2015, de 30 de marzo, de control de la actividad económico-financiera de los partidos políticos (que a su vez modifica las Leyes Orgánicas 6/2002 y 8/2007, en este último caso por segunda vez), y también, de manera indirecta, la Ley de Transparencia antes citada.

El sistema de financiación de las formaciones políticas experimentó un importante cambio tras la aprobación de la mencionada Ley Orgánica 8/2007 (en adelante, LFPP), que instauró un régimen de financiación consistente en la implantación de un sistema mixto, mediante el que las formaciones políticas pasaban a tener dos fuentes de ingresos directas: pública y privada. La financiación pública pasó a constituir el grueso de los recursos que reciben las formaciones políticas, proviniendo principalmente de subvenciones directas que los partidos políticos reciben del Estado para realizar sus actividades, tales como los gastos de funcionamiento ordinario o los concernientes a seguridad (Gavilanes y Andrés, 2016). En cuanto a la financiación privada, la misma procede de las aportaciones de los afiliados, junto con las donaciones que los partidos políticos reciben, teniendo éstas últimas ciertas limitaciones con el objetivo principal de que ningún partido político pueda obtener un volumen de financiación privada en exceso, que le haga disfrutar de una posición ventajosa frente al resto (Sevillano y Barrón, 2019).

Otro de los principales cambios que supuso la entrada en vigor de la LFPP fue la obligación de las formaciones políticas de remitir al Tribunal de Cuentas todo lo referente a su actividad económica en los plazos y forma establecidos (LFPP, art. 14.6), además de estar obligadas a incluir sus cuentas anuales en su página web en el plazo máximo de un mes desde la fecha de su presentación al citado órgano (LFPP, art. 14.8).

En el contexto descrito, el presente trabajo se centra en el análisis de la transparencia organizativa y económica de las formaciones políticas mostrada a través de sus páginas web, según lo dispuesto en la Ley de Transparencia, centrando el marco teórico del estudio en la información que deben facilitar los partidos políticos, para cuyo análisis se diseñaron sendos índices de transparencia según lo establecido en el artículo 14 de la LFPP y la mencionada Ley de Transparencia, tomando como referencia medidas similares aplicadas a dichos entes, así como a otras entidades del sector no lucrativo (Díez et al., 2019; Del Campo et al., 2016).

El resto del trabajo se estructura de la siguiente forma: en la sección segunda se incluye el marco teórico del estudio, mientras que la sección tercera recoge el estudio empírico y la discusión de los resultados, definiéndose en la misma los índices de transparencia objeto de evaluación, así como sus resultados estadísticos junto con el estudio econométrico que relaciona la eficiencia organizativa con la económica. Finalmente, en la sección cuarta se recogen las principales conclusiones del trabajo.

\section{El concepto de transparencia y su de desarrollo: publicidad activa y buen gobierno}

La transparencia hace referencia a la posibilidad que tiene cualquier persona interesada en disponer de información de una determinada organización, gobierno o empresa, de manera que se facilite la toma de decisiones a los destinatarios de dicha información sin que se generen problemas de asimetría informativa ${ }^{4}$. En la definición ofrecida por la OCDE se establece que cuando hablamos de transparencia, no sólo nos

El concepto de asimetría informativa hace referencia a una posición desigual en cuanto a la calidad y cantidad de información entre las partes que intervienen en una determinada transacción, provocando que una de las partes tenga, o más información, o de mayor calidad que la otra, dando lugar a una situación ventajosa para la primera (Cavaller, 2017). 
referimos a la misma en el ámbito privado, puesto que en el ámbito público también tiene importancia capital, como por ejemplo, la de los gobiernos, y ese sentido, se han llevado a cabo diversos estudios que tratan de medir el nivel de transparencia tanto en el ámbito público (Hermosa et al., 2017) como en el privado (Arredondo et al., 2014).

Puntualizando en el sector público, la transparencia se ha convertido en "un indicador fundamental de la calidad de los gobiernos democráticos" (Transparencia Castilla-La Mancha, 2020), debido a que fomentando el acceso y la participación de la sociedad a la información, se favorece la imagen de la organización, y se contribuye a la consecución de los objetivos organizacionales. A sensu contrario, se puede concluir que la carencia de transparencia en entidades como las formaciones políticas da lugar a una pérdida de apoyos, con el consiguiente fracaso organizacional (Del Campo et al., 2016).

Tomando como referencia a los países europeos que son líderes en materia de transparencia en todo el mundo durante las últimas décadas, tales como Dinamarca, Suecia, Países Bajos o Noruega (Transparencia Internacional España, 2017), en España se ha producido un aumento de la cultura de transparencia tanto a nivel público como privado, incluyendo de este modo también a los partidos políticos, (Acess Info, 2019), en cuyo ámbito, el primer elemento fundamental del cambio fue la aprobación de la mencionada LFPP en el año 2007, que consolidó la transformación de su sistema de financiación, convirtiéndolos en receptores de subvenciones públicas (Rodríguez, 2011, 2012 y 2014), cuyos importes se gradúan en función de su representatividad. En este sentido, el hecho de que la mayor parte de la financiación que reciben los partidos políticos haya pasado a ser pública, hace necesaria la rendición de cuentas por parte de éstos (Rodríguez y Fidalgo, 2010, 2011 y 2012) con el objetivo de poder analizar si se destinan dichos fondos a los fines previstos, no estando la aplicación de los mismos relacionada con la obtención de un resultado electoral concreto, sino con el ejercicio de una actividad política correcta y en mesura a las necesidades de la masa social a la que representan las formaciones políticas (Rodríguez, 2018).

Esta preocupación por una mayor transparencia ha venido dada, entre otras cuestiones anteriormente comentadas, por la mayor inquietud de la ciudadanía de disponer de información objetiva para la toma de decisiones, aunque todavía España se sitúa muy lejos de los primeros puestos del ranking de países más transparentes, como lo demuestra un reciente estudio realizado por la Organización de Transparencia Internacional en 2018 para determinar el Índice de Percepción de la Corrupción en el sector público de 180 países y territorios, estableciéndose un ranking mundial de transparencia de los países, en el que España obtuvo el puesto $41^{\circ}$ (58 puntos), detrás de países como Taiwán, Qatar, Botswana o Israel (Expansión, 2018).

La modernización de la Administración ha sido uno de los principales hechos que han fomentado este cambio en el paradigma de la transparencia, gracias especialmente a la aparición de los medios electrónicos, lo que ha supuesto un cambio fundamental en el acceso a la información, pues gracias a las nuevas herramientas tecnológicas, los usuarios pueden disponer de cualquier tipo de datos con inmediatez y a un coste relativamente bajo.

Otros conceptos importantes que introduce la propia Ley de Transparencia son los de publicidad activa y buen gobierno. Así, la "publicidad activa" está relacionada con una actividad constante de transparencia, mediante la que los sujetos obligados publican de forma periódica y actualizada información relevante relativa a su actividad a través de medios electrónicos de una manera clara, estructurada y entendible, mientras que el "buen gobierno" se refiere a la actuación de los responsables de la gestión de los organismos obligados por dicha ley (entre ellos los partidos políticos), que en todo caso debe ser diligente, transparente e imparcial.

Con el objetivo de poder materializar los conceptos mencionados, que pueden parecer, a priori, meramente teóricos, y también para hacer la transparencia más accesible a la ciudadanía, una de las medidas que se implantó fue la creación del denominado "Portal de Transparencia" por parte de los sujetos obligados, es decir, todas aquellas organizaciones y entidades obligadas por la normativa tienen la obligación de crear un lugar específico en sus sitios web dedicado única y exclusivamente a la transparencia de la entidad, con el objetivo de facilitar la identificación y la búsqueda de información por parte de cualquier usuario interesado (Ley de Transparencia, art. $2^{\circ}$ y $3^{\circ}$ ). En concreto, los entes obligados al cumplimiento de la publicidad activa y el buen gobierno deben llevar a cabo la publicación actualizada de información acerca de su estructura, organización, principales cargos y sueldos de éstos, así como sobre cuestiones económicas relacionadas especialmente con la rendición de cuentas.

Durante los últimos años han sido diferentes las organizaciones que han llevado a cabo apuestas por el desarrollo de la transparencia de las formaciones políticas a través de evaluaciones de su situación, propuestas para su mejora, y el establecimiento de rankings de formaciones más transparentes. Entre dichos entes se encuentran Transparencia Internacional España (2017) y la Fundación Compromiso y Transparencia (2017), respecto de cuyo índice el trabajo de Martisi (2016) concluye que los partidos políticos todavía no han interiorizado la transparencia y la rendición de cuentas como una obligación más de sus responsabilidades públicas, defendiendo la organización política Por Un Mundo Más Justo $(\mathrm{M}+\mathrm{J})(2019)$ que la transparencia "guarda una relación directa con el empoderamiento de la ciudadanía, que refuerza su 
participación en los asuntos públicos gracias a la puesta en marcha de canales y herramientas que permiten acceder a la información antes oculta o incluso vetada".

Asimismo, y debido al cambio en el escenario político, han sido numerosos los estudios que han llevado a cabo una medición de la transparencia en el panorama político español de diversas formas. En ese aspecto, Díez et al. (2019) realizan un estudio de la transparencia como un elemento más de las estrategias de campaña electoral de las formaciones políticas, mientras que Hollyer et al. (2011) analizan la relación que existe entre transparencia y democracia, señalando el trabajo de Christensen y Cheney (2015) que la transparencia puede ser la solución a diversos problemas de la sociedad actual, tales como la corrupción política y la desconfianza en las instituciones.

De otra parte, diversos estudios reportan retornos positivos acerca de las actividades de transparencia de los partidos políticos. Así, el trabajo de Ball (2009) defiende que la publicación de acciones abiertas por parte de los responsables de la gestión política puede ayudar a combatir la corrupción, mientras que Harrison y Sayogo (2014) concluyen que una de las más importantes consecuencias de la transparencia es la obligación a la que se someten los políticos de hacerse responsables de sus actuaciones y cumplir sus promesas. Por último, el trabajo de Dader et al. (2011) analiza la finalidad para la que son utilizadas las páginas web de las formaciones políticas, defendiendo la necesidad de un mayor enfoque "transparentista" en detrimento de la promoción de la actividad política, así como de una reducción de la opacidad de la información dentro de la misma web del partido.

En ese sentido, cabe precisar que la finalidad para la que ha sido utilizada la página web de los partidos políticos ha ido evolucionando a lo largo del tiempo, lo que ha sido provocado por diversos factores, como la aparición en su momento de nuevas herramientas de difusión e interacción, tales como blogs, portales de distribución de videos y cuentas de nanoblogs como Twitter, tal y como exponen en su investigación Dader et al. (2011), quiénes señalan que resulta paradójico que estas entidades utilicen la herramienta web para las funciones persuasivo-propagandísticas para las que están peor dotadas en comparación con los formatos mediáticos tradicionales u otros recursos de las nuevas tecnologías, y en cambio, aprovechen menos la funcionalidad para la que apenas tienen rival en los restantes soportes y canales.

Fue entre mediados y finales de la década de los 2000 cuando, debido a la aprobación de la mencionada LFPP y la intención del gobierno nacional de promulgar una ley de transparencia, junto a la creciente voluntad ciudadana de tener más información acerca de este tipo de asuntos, lo que obligaría, entre otros, a los partidos políticos, a cambiar la estrategia de sus páginas web. Así, las páginas web, que comenzaron a desarrollarse como espacios de comunicación abierta entre la formación política y el grupo de interés, y en las que se fomenta un diálogo abierto entre todas las partes, toman posteriormente especial importancia en asuntos como la transparencia económica y organizacional, quedando de esta forma atrás, aunque no de manera absoluta, la utilización de las webs como medio propagandístico con el objetivo de reforzar al partido (ideario, historia, programa, etc). En este sentido, el estudio llevado a cabo por Larrondo (2016) pone de manifiesto que se puede apreciar un nuevo estilo en cuanto a la gestión del espacio web de las formaciones políticas, el cual ya es reconocido como un espacio público que debe ser utilizado tanto para reforzar su mensaje político, como para comunicarse con los ciudadanos, dando y recibiendo información recíprocamente.

A pesar del tiempo trascurrido desde la entrada en vigor en el año 2013 de la Ley de Transparencia, son diversos los estudios que, como posteriormente veremos, plantean la necesidad de materialización de la norma como ayuda a las entidades obligadas, entre las que se encuentran la Administración Pública y el conjunto de entidades privadas receptoras de subvenciones públicas, puesto que la transparencia implica la comunicación proactiva con los ciudadanos para dar cumplimiento al contenido de los conceptos de publicidad activa y buen gobierno anteriormente definidos, sin que al margen de los citados conceptos fundamentales de transparencia exista una norma que obligue a las formaciones políticas a la publicación de documentos concretos con el objetivo de ser transparentes de cara a los grupos de interés, cuestión que ha sido denunciada por diversos organismos desde la aprobación de la norma. Así, De Lorenzo (2017) afirma que "esta regulación ha resultado insuficiente en la actualidad y no satisface las exigencias sociales y políticas del momento", mientras que el estudio llevado a cabo por Morales et al. (2016, p. 96) establece que el hecho de la promulgación de la ley no supone un aumento de la transparencia, argumentando que "en muchos casos la demanda o necesidad de una norma indica la situación problemática de las cuestiones a las que hace referencia”. En esta misma línea de opinión, Cavanna (2014) criticó la aprobación de la Ley de Transparencia alegando que la misma trata de regular tres temas muy diferentes y complejos, y que "el problema de ser tan ambicioso es que al final se pierde foco y se termina disparando a todo lo que se mueve, sin mucho criterio ni sentido".

Por lo expuesto, diversas organizaciones como la Fundación Ciudadana Civio (2019), trabajan con el objetivo de luchar por medidas más concretas en cuanto a transparencia se refiere, y con ese fin una de las iniciativas que esta organización ha llevado a cabo ha sido enviar, en repetidas ocasiones, propuestas para mejorar el texto de la Ley de Transparencia, por considerar que "es insuficiente y sigue sin aclarar cómo aplicar la norma y qué limita su alcance". 
En síntesis, a tenor de la legislación vigente y la literatura revisada, se observa la ausencia de un sistema de evaluación de la transparencia, junto con un régimen sancionador para aquellas organizaciones que no cumplan con sus deberes, por lo que es de esperar que en un futuro no demasiado lejano se modifique oportunamente la normativa en vigor para dar cabida a las reivindicaciones expuestas en aras de un mayor y mejor nivel de transparencia de los sujetos obligados.

\section{Materiales y métodos}

El diseño del estudio se planteó en tres fases principales: inicialmente se llevó a cabo la estructuración de los índices de transparencia relacionados con los aspectos organizativos y económicos respectivamente, a partir de cuyos resultados se realizó posteriormente el correspondiente análisis de los principales estadísticos descriptivos de dichas variables, practicándose en una última fase un estudio econométrico para conocer la posible relación de causalidad entre los índices de transparencia previamente evaluados.

\subsection{Diseño de los índices de transparencia: organizativa y económica}

Para evaluar los niveles de transparencia de las formaciones políticas en base a la información publicada en sus páginas web, se estructuraron sendos cuestionarios sobre la base de las investigaciones llevadas a cabo por Transparencia Internacional (2017). En este sentido, el análisis cualitativo de la información ofrecida por las formaciones políticas parte de la premisa de que todas ellas están obligadas a tener disponible una página web, tal como recoge en su art. 3 la Ley Orgánica 6/2002, de 27 de junio, de partidos políticos (en adelante Ley de partidos políticos), habiéndose diseñado en concreto dos índices de transparencia: el Índice de Transparencia Organizativa (ITO) y el Índice de Transparencia Económica (ITE).

Centrándonos en el Índice de Transparencia Organizativa (ITO), para su diseño se tomó en consideración la información suministrada por las formaciones políticas en sus páginas web respecto a las siguientes cuestiones:

1. Información sobre el partido político: fundación, estructura y procedimientos actuales de la formación.

2. Información sobre máximos cargos e integrantes del partido: procedimientos de elección de los máximos cargos, e información de los actuales.

3. Información sobre entidades vinculadas, afiliados y ciudadanía: conjunto de entidades vinculadas al partido.

4. Comunicación pública en la web del partido: capacidad de interacción en la web del partido.

5. Funcionalidad del sitio web del partido político: información técnica acerca de la experiencia de navegación que ofrece la web del partido político.

De acuerdo con lo anterior, el ITO queda desglosado en 5 subíndices $\left(\mathrm{S}_{\mathrm{i}}\right)$, cada uno de los cuales está compuesto a su vez por un conjunto de ítems $\left(\mathrm{S}_{\mathrm{ij}}\right)$ mediante los que se evalúan diferentes aspectos concretos relativos a las cuestiones de organización del partido político. El Apéndice 1 recoge el desglose de los diferentes ítems que conforman el ITO.

Cuantitativamente cada ítem $\left(S_{\mathrm{ij}}\right)$ toma un valor igual a la unidad divida por el número de ítems que lo componen $(\mathrm{m})\left(\mathrm{S}_{\mathrm{ij}}=1 / \mathrm{m}\right)$, de forma que la suma de cada subíndice sería igual a la 1 , tal como se muestra en la expresión (1):

$$
\mathrm{S}_{\mathrm{i}}=\sum_{\mathrm{j}=1}^{\mathrm{m}} \mathrm{S}_{\mathrm{ij}}=1
$$

En consecuencia, el ITO será igual a la suma de los valores de los cinco subíndices previamente calculados, pudiendo alcanzar un valor máximo de 5 puntos, que expresado en porcentaje se puede obtener según la formulación que se recoge en la expresión (2):

$$
\mathrm{ITO}_{\mathrm{i}}=\left(\sum_{\mathrm{i}=1}^{5} \mathrm{~S}_{\mathrm{i}}\right) *(100 / 5)
$$

En síntesis, el ITO expresa en tanto por cien el porcentaje de transparencia informativa organizacional recogida en la web del partido político correspondiente a partir del resultado obtenido en cada subíndice $\left(S_{\mathrm{ij}}\right)$.

En cuanto al Índice de Transparencia Económica (ITE), para su obtención se evaluaron 11 aspectos relacionados con la rendición de cuentas, en función a las obligaciones que establecen la Ley FPP y la Ley de Transparencia. El suministro de este tipo de información está relacionado con el contenido de las cuentas anuales, la información detallada de las partidas de gastos e ingresos, y las operaciones relativas a créditos o préstamos de instituciones financieras, entre otras. El Apéndice 2 incluye los diferentes ítems que conforman 
el ITE, no habiéndose considerado necesaria su subdivisión en subíndices por tratarse de un tema de rendición de cuentas.

En consecuencia, el ITE será igual a la suma de los valores de sus ítems, pudiendo alcanzar un valor máximo de 11 puntos, que porcentualmente se puede calcular de acuerdo con la formulación recogida en la expresión (3):

$$
\operatorname{ITE}_{\mathrm{i}}=\left(\sum^{11}{ }_{\mathrm{i}=1} \mathrm{I}_{\mathrm{i}}\right) *(100 / 11)
$$

\subsection{Muestra}

Para llevar a cabo la investigación se seleccionó una muestra de partidos políticos con representación parlamentaria en la actualidad o en legislaturas anteriores a la presente de 2019, entidades todas ellas obligadas, por tanto, a mantener los niveles de transparencia exigidos por la legislación vigente, de acuerdo al contenido del artículo 14 de la Ley FPP anteriormente comentado.

La visita a las distintas páginas web se realizó a lo largo del primer trimestre del año 2020. El Cuadro 1 recoge las formaciones políticas seleccionadas, ordenadas por orden alfabético, junto con su dirección web:

Cuadro. 1. Partidos políticos con representación parlamentaria

\begin{tabular}{|c|}
\hline 1. ANOVA IRMANDADE NACIONALISTA (www.anova.gal, 2020) \\
\hline 2. $\quad$ BARCELONA EN COMU (www.barcelonaencomu.cat, 2020) \\
\hline 3. CATALUNYA EN COMU (www.catalunyaencomu.cat, 2020) \\
\hline 4. CIUDADANOS-PARTIDO DE LA CIUDADANIA (www.ciudadanos-cs.org, 2020) \\
\hline $\begin{array}{l}\text { 5. } \text { COALICIÓ COMPROMÍS: BLOC-INICIATIVA-VERDS (www.compromis.net, 2020) } \\
\text { 6. }\end{array}$ \\
\hline 6. COALICIÓN CANARIA (www.coalicioncanaria.org, 2020) \\
\hline $\begin{array}{llccc}7 . & \text { CONVERGENCIA } & \text { DEMOCRÁTICA } & D E & \text { CATALUNYA } \\
\text { (https://web.archive.org/web/20160614225752/http://www.convergencia.cat, , 2020) }\end{array}$ \\
\hline 8. $\quad E Q U O$ (www.partidoequo.es, 2020$)$ \\
\hline 9. ESQUERRA REPUBLICANA DE CATALUNYA (www.esquerra.cat, 2020) \\
\hline 10. ESQUERRA UNIDA DEL PAIS VALENCIA (EUPV) (www.eupv.org, 2020) \\
\hline 11. ESQUERRA UNIDA I ALTERNATIVA (www.semprealesquerra.cat, 2020) \\
\hline 12. EUSKO ALDERDI JELTZALEA-PARTIDO NACIONALISTA VASCO (www.eaj-pnv.eus, 2020) \\
\hline 13. EUSKAL HERRIA BILDU (www.ehbildu.eus, 2020) \\
\hline 14. FORO DE CIUDADANOS (www.foroasturias.es, 2020) \\
\hline 15. IZQUIERDA UNIDA (www.izquierdaunida.org, 2020) \\
\hline 16. MÁS PAÍS (www.maspais.es, 2020) \\
\hline 17. NUEVA CANARIAS - NUEVA GRAN CANARIA (www.nuevacanariaslpgc.org, 2020) \\
\hline 18. PARTIDO ARAGONÉS (http://www.partidoaragones.es/, 2020) \\
\hline 19. PARTIDO POPULAR (www.pp.es, 2020) \\
\hline 20. PARTIDO REGIONALISTA DE CANTABRIA (www.prc.es, 2020) \\
\hline 21. PARTIDO SOCIALISTA OBRERO ESPAÑOL (www.psoe.es, 2020) \\
\hline 22. PARTIT DELS SOCIALISTES DE CATALUNYA (www.socialistes.cat, 2020) \\
\hline 23. PARTIT DEMOCRATA EUROPEU CATALA (www.partitdemocrata.cat, 2020) \\
\hline 24. PODEMOS (www.podemos.info, 2020) \\
\hline 25. SOBIRANISTES (www.sobiranistes.cat, 2020) \\
\hline 26. TERUEL EXISTE (www.teruelexiste.info, 2020) \\
\hline 27. UNIÓN DEL PUEBLO NAVARRO (www.upn.org, 2020) \\
\hline 28. UNIÓN PROGRESO Y DEMOCRACIA (UPyD) (www.upyd.es, 2020) \\
\hline 29. VOX (www.voxespana.es, 2020) \\
\hline
\end{tabular}

Fuente: Elaboración propia. 
Se obtuvo una muestra total de 29 partidos políticos con representación parlamentaria presente o pretérita, cuyas páginas webs fueron objeto de análisis para conocer sus niveles de transparencia, de acuerdo con el diseño de los índices propuestos a tal efecto en el presente trabajo (Apéndices 1 y 2).

\subsection{Resultados y discusión}

\subsubsection{Análisis estadístico descriptivo}

Tras el correspondiente trabajo de campo llevado a cabo, visitando de forma exhaustiva cada una de las páginas webs de los 29 partidos políticos seleccionados para examinar el cumplimiento de los cuestionarios propuestos en lo que se refiere a los índices de ITO e ITE, el Cuadro 2 recoge los estadísticos descriptivos de las citadas variables, incluyendo en lo que se refiere al ITO, además de sus valores globales, los correspondientes a cada uno de los subíndices que lo componen.

Cuadro. 2. Descriptivos de los Índices ITE e ITO (incluidos $\left.\mathrm{S}_{\mathrm{i}}\right)^{5}$

\begin{tabular}{|c|c|c|c|c|c|}
\hline Variable & Media & Desv.típica & Mínimo & Máximo & $\mathbf{N}$ \\
\hline Transparencia económica (ITE) & 4,79 & 3,23 & 0,00 & 11,00 & 29 \\
\hline Transparencia organizativa (ITO) & 2,10 & 0,96 & 0,39 & 3,61 & 29 \\
\hline $\begin{array}{l}\text { Transparencia organizativa: Información } \\
\text { sobre el partido político }\left(\mathrm{S}_{1}\right)\end{array}$ & 0,63 & 0,28 & 0,00 & 1,00 & 29 \\
\hline $\begin{array}{l}\text { Transparencia organizativa: Información } \\
\text { sobre máximos cargos e integrantes del } \\
\text { partido }\left(S_{2}\right)\end{array}$ & 0,37 & 0,27 & 0,00 & 0,75 & 29 \\
\hline 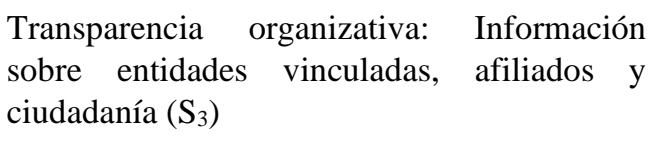 & 0,45 & 0,36 & 0,00 & 1,00 & 29 \\
\hline $\begin{array}{l}\text { Transparencia organizativa: Comunicación } \\
\text { pública en la web del partido }\left(\mathrm{S}_{4}\right)\end{array}$ & 0,46 & 0,20 & 0,00 & 0,66 & 29 \\
\hline $\begin{array}{l}\text { Transparencia organizativa: Funcionalidad } \\
\text { web del sitio del partido político }\left(\mathrm{S}_{5}\right)\end{array}$ & 0,66 & 0,17 & 0,26 & 0,95 & 29 \\
\hline
\end{tabular}

Fuente: Elaboración propia

La información recogida en el Cuadro 2 pone de manifiesto en lo que a transparencia organizacional se refiere que los partidos políticos informan con cierta parquedad a tenor del valor promedio del ITO, que tan solo alcanza un valor medio de 2,10 sobre un máximo de 5 puntos.

Analizada la transparencia organizacional por subíndice $\left(\mathrm{S}_{\mathrm{i}}\right)$, se observa que el aspecto más desarrollado es el de la funcionalidad de la web $\left(\mathrm{S}_{5}=0,66\right)$, probablemente porque la mayoría de los partidos disponen de página Web $2.0^{6}$, seguido de cerca por la información del partido político $\left(\mathrm{S}_{1}=0,63\right)$. De lo anterior se deduce que prima más la funcionalidad de la web que los contenidos ofrecidos en la misma, lo que se evidencia por la menor puntuación que obtienen el resto de los subíndices.

En cuanto al índice de transparencia económica (ITE), en línea con los resultados obtenidos sobre la transparencia organizativa, también se atisban en promedio valores relativamente bajos, situándose concretamente en 4,79 puntos sobre un máximo de 11. La situación descrita se justifica porque algunas de las

\footnotetext{
El análisis estadístico y econométrico se llevó a cabo con la aplicación SPSS, versión 22.

La Web 2.0 o Web social es una "denominación de origen" que se refiere a una segunda generación en la historia de los sitios web. Su denominador común es que están basados en el modelo de una comunidad de usuarios, abarcando una amplia variedad de redes sociales, blogs, wikis y servicios multimedia interconectados, cuyo propósito es el intercambio ágil de información entre los usuarios y la colaboración en la producción de contenidos. Todos estos sitios utilizan la inteligencia colectiva, para proporcionar servicios interactivos en la red, donde el usuario tiene control para publicar sus datos y compartirlos con los demás, entendiéndose por inteligencia colectiva el conocimiento general de todos los individuos para participar de dichas páginas web (Instituto Nacional de Tecnologías Educativas y Formación del Profesorado, 2020).
} 
formaciones políticas presentan una información muy escueta y desactualizada en este campo, mientras que otras optan directamente por no publicar este tipo de información.

Para profundizar en los niveles de transparencia organizativa y económica alcanzados por los partidos políticos, se llevó a cabo una reclasificación de dichas entidades en las categorías de "Más transparentes", "Medianamente transparentes" y "Menos transparentes", que estuvo basada de forma segregada en los índices evaluados ITO e ITE. En este sentido, las formaciones políticas se catalogaron como "menos transparentes" cuando sus webs ofrecían un nivel de información inferior al 50\% del requerido, mientras que aquellas que alcanzaron en los citados índices valores entre el $50 \%$ y $75 \%$ se clasificaron como "medianamente transparentes", y finalmente, aquellas otras que reportaron un valor superior al $75 \%$ fueron incluidas dentro del grupo de "más transparentes".

El Cuadro 3, junto con los Gráficos 1 y 2, contiene la información sobre el análisis realizado en base a la reclasificación propuesta.

Cuadro. 3. Descriptivos de los subíndices ITO y del ITE

\begin{tabular}{|l|c|c|c|c|c|}
\hline \multicolumn{7}{|c|}{ Panel A: Partidos Políticos “más transparentes” } \\
\hline \multicolumn{1}{|c|}{ Variable } & Media & Desv.típica & Mínimo & Máximo & N \\
\hline Transparencia organizativa (S) & 3,18 & 0,23 & 3,01 & 3,61 & 8 \\
Transparencia económica (I) & 9,40 & 0,89 & 9,00 & 11,00 & 5 \\
\hline \multicolumn{6}{|c|}{ Panel B: Partidos Políticos “medianamente transparentes” } \\
\hline Variable & Media & Desv.típica & Mínimo & Máximo & N \\
\hline Transparencia organizativa (S) & 2,43 & 0,38 & 1,85 & 2,94 & 9 \\
Transparencia económica (I) & 7,17 & 1,33 & 6,00 & 9,00 & 6 \\
\hline \multicolumn{6}{|c}{ Panel C: Partidos Políticos “menos transparentes” } \\
\hline Variable & Media & Desv.típica & Mínimo & Máximo & N \\
\hline Transparencia organizativa (S) & 1,14 & 0,50 & 0,39 & 1,79 & 12 \\
Transparencia económica (I) & 2,83 & 2,23 & 0,00 & 5,00 & 18 \\
\hline
\end{tabular}

Fuente: Elaboración propia

De la información suministrada por el Cuadro 3 se desprende en lo que respecta a los partidos políticos más transparentes, que el $28 \%$ alcanza dicha categoría en transparencia organizacional, descendiendo dicho porcentaje a tan sólo el $17 \%$ en transparencia económica, tendencia que se repite en la categoría de partidos medianamente transparentes (31\% vs. $21 \%$ ) y menos transparentes ( $41 \%$ vs. $62 \%$ ), denotándose una mayor opacidad en la esfera económica frente a la organizacional, si bien, en síntesis, se puede afirmar que la información suministrada por las formaciones políticas muestra bajos niveles de transparencia en general.

Gráfico. 1. Descriptivos Índice de Transparencia Económica (ITE)

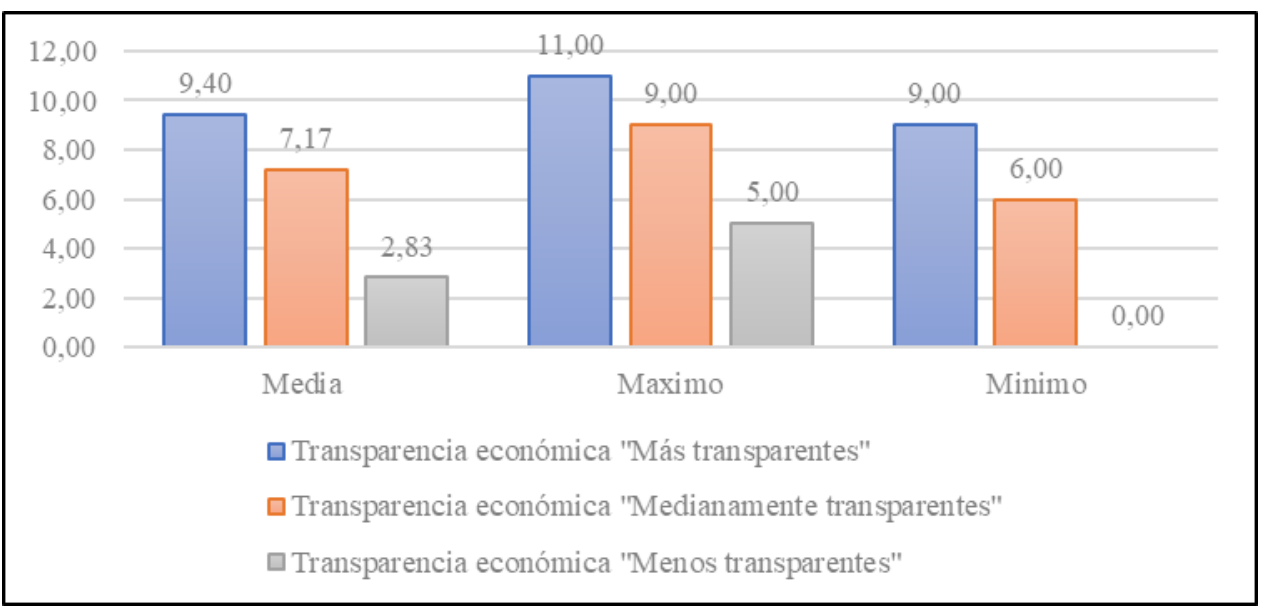

Fuente: Elaboración propia. 
Gráfico. 2. Descriptivos Índice de Transparencia Organizativa (ITO)

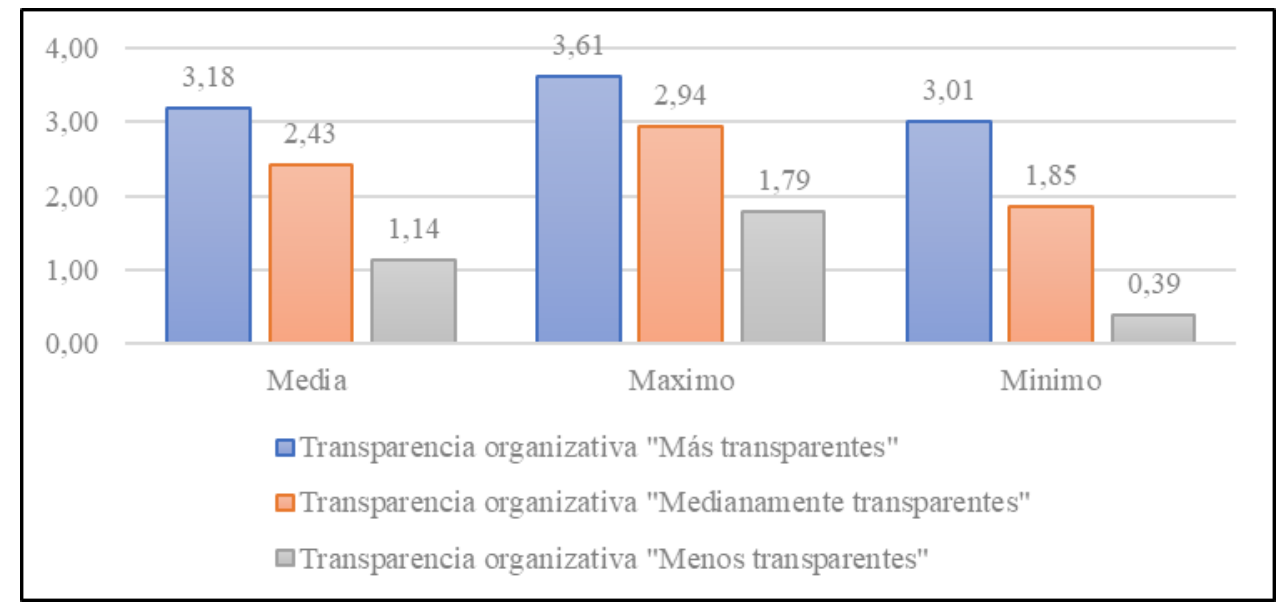

Fuente: Elaboración propia.

\subsubsection{Análisis econométrico}

Del análisis estadístico precedente (Cuadro 3) se deduce que la producción de información económica presentada por los partidos políticos aumenta conforme progresa la información organizativa, y en ese sentido, para analizar el comportamiento de la variable ITE como variable explicada del ITO a través de sus diversos subíndices $\left(\mathrm{S}_{\mathrm{i}}\right)$, se aplicó el modelo de regresión lineal incluido en la expresión (4), aceptándose como hipótesis nula $\left(\mathrm{H}_{0}\right)$ la no existencia de relación entre el índice de transparencia económica (ITE) y las variables relativas a los subíndices de transparencia organizativa $\left(\mathrm{S}_{\mathrm{i}}\right)$, lo que implicaría que las variables explicativas utilizadas en el modelo no aportan información relevante al análisis de regresión proyectado.

$$
\mathrm{ITE}=\beta_{0}+\beta \mathrm{S}
$$

Considerando que el índice de transparencia organizativa se ha dividido en cinco variables explicativas o subíndices $\left(\mathrm{S}_{\mathrm{i}}\right)$, el detalle del modelo de regresión lineal propuesto inicialmente es el que se recoge en la expresión (5):

$$
\mathrm{ITE}=\beta_{0}+\beta_{1} \mathrm{~S}_{1}+\beta_{2} \mathrm{~S}_{2}+\beta_{3} \mathrm{~S}_{3}+\beta_{4} \mathrm{~S}_{4}+\beta_{5} \mathrm{~S}_{5}+\varepsilon
$$

donde "ITE" es la variable dependiente que representa la transparencia económica en cada una de las formaciones políticas, mientras que las variables independientes se refieren respectivamente a cada uno de los subíndices que conforma la transparencia organizativa mostrada en la web según el siguiente detalle (Apéndice 1):

"S,": Transparencia relativa a información sobre el partido político.

"S $\mathrm{S}_{2}$ ": Transparencia relativa a información sobre máximos cargos e integrantes del partido.

"S $\mathrm{S}_{3}$ ": Transparencia relativa a información sobre entidades vinculadas, afiliados y ciudadanía.

"S4": Comunicación pública en la web del partido político.

"S5": Funcionalidad del sitio web del partido político.

Para el análisis de normalidad de las variables explicativas, teniendo en cuenta el reducido número de componentes de la muestra ( $\mathrm{N}=29)$, se utilizó el test de Shapiro Wilk, cuya hipótesis nula acepta que los datos de las variables proceden de poblaciones que siguen una distribución normal (Cárdenas, 2014). Los resultados de dicho test se recogen en el Cuadro 4: 
Cuadro. 4. Test de normalidad de Shapiro-Wilk $(\mathrm{N}=29)$

\begin{tabular}{|c|c|c|c|}
\hline Variables & Estadístico & gl & Sig. \\
\hline S1 & 0,931 & 29 & 0,060 \\
\hline S2 & 0,876 & 29 & 0,003 \\
\hline S3 & 0,893 & 29 & 0,007 \\
\hline S4 & 0,831 & 29 & 0,000 \\
\hline S5 & 0,917 & 29 & 0,025 \\
\hline
\end{tabular}

Fuente: SPSS, versión 22

De acuerdo a la información contenida en el Cuadro 4, al realizar la prueba de normalidad se observa que las distribuciones de las variables no son normales (excepto en el caso de la variable $S_{1}$ ), lo que se debe principalmente a la existencia de formaciones poco transparentes, con bajos niveles de respuesta, por lo que se realizó una búsqueda de posibles outliers aplicando el criterio de la diferencia entre los cuartiles tercero y primero multiplicado por el coeficiente 1,5, con el fin de detectar posibles valores anómalos por debajo del cuartil 1 o por encima del cuartil 3 (Martín et al., 2008). El resultado obtenido fue que para la variable $\mathrm{S}_{5}$ se encontraron dos valores atípicos que desvirtuaban la muestra, lo cual dio lugar a los primeros indicios de la existencia de formaciones políticas que aportaban poca información y desconfiguraban el análisis.

De otra parte, como complemento a la búsqueda de outliers, se llevó a cabo un análisis de los resultados reflejados por las formaciones políticas en los cuestionarios previos y su comparación con la media global, considerando a las formaciones que más se alejaban de la media como posibles candidatos a salir del modelo, concluyendo este estudio adicional que se debían excluir de la muestra cinco formaciones políticas debido a los bajos niveles de información que aportaban, quedando de esta forma reducida a 24 formaciones políticas.

Realizado nuevamente el test de normalidad, cuyos resultados se muestran en el Cuadro 5, se observa una mejora en la normalidad de las variables, pudiendo identificarse ahora tres variables $\left(S_{1}, S_{3}\right.$, y $\left.S_{5}\right)$ con un coeficiente de significación mayor que 0,05 , lo que permite aceptar la hipótesis nula del test.

Cuadro. 5. Test de normalidad de Shapiro-Wilk $(\mathrm{N}=24)$

\begin{tabular}{|c|c|c|c|}
\hline Variables & Estadístico & gl & Sig. \\
\hline $\mathbf{S}_{\mathbf{1}}$ & 0,922 & 24 & 0,064 \\
\hline $\mathbf{S}_{\mathbf{2}}$ & 0,909 & 24 & 0,034 \\
\hline $\mathbf{S}_{\mathbf{3}}$ & 0,919 & 24 & 0,055 \\
\hline $\mathbf{S}_{\mathbf{4}}$ & 0,844 & 24 & 0,002 \\
\hline $\mathbf{S}_{\mathbf{5}}$ & 0,918 & 24 & 0,052 \\
\hline
\end{tabular}

Fuente: SPSS, versión 22

A partir de las variables seleccionadas, se analizaron las correlaciones entre las mismas con el objetivo de determinar posibles problemas de multicolinealidad, a cuyos efectos se calculó el coeficiente de correlación de Pearson, cuyos resultados se incluyen en el Cuadro 6, pudiendo concluirse que dichas variables no están correlacionadas de forma importante, lo que permite su selección para ser introducidas en el modelo regresión propuesto.

Cuadro. 6. Coeficiente de correlación de Pearson

\begin{tabular}{|c|c|c|c|}
\hline Variables & $\mathbf{S}_{\mathbf{1}}$ & $\mathbf{S}_{\mathbf{3}}$ & $\mathbf{S}_{\mathbf{5}}$ \\
\hline $\mathbf{S}_{\mathbf{1}}$ & 1 & $0,563 * *$ & $-0,14$ \\
\hline $\mathbf{S}_{\mathbf{3}}$ & $-\ldots--$ & 1 & 0,025 \\
\hline $\mathbf{S}_{\mathbf{5}}$ & $-\ldots--$ & $-\ldots--$ & 1 \\
\hline
\end{tabular}

Notas: Nivel de significación: ** $1 \%$.

Fuente: SPSS, versión 22 
De acuerdo con los análisis de normalidad y multicolinealidad precedentes, se procedió a estimar el modelo de regresión que recoge la expresión (6), cuyos resultados se muestran en los Cuadros 7, 8 y 9.

$$
\mathrm{ITE}=\beta_{0}+\beta_{1} \mathrm{~S}_{1}+\beta_{3} \mathrm{~S}_{3}+\beta_{5} \mathrm{~S}_{5}+\varepsilon
$$

Cuadro. 7. Resumen del modelo de regresión lineal múltiple

\begin{tabular}{|c|c|c|c|c|}
\hline $\mathbf{R}$ & $\begin{array}{c}\mathbf{R} \\
\text { cuadrado }\end{array}$ & $\begin{array}{c}\text { R cuadrado } \\
\text { ajustado }\end{array}$ & $\begin{array}{c}\text { Error estándar de la } \\
\text { estimación }\end{array}$ & $\begin{array}{c}\text { Durbin- } \\
\text { Watson }\end{array}$ \\
\hline 0,663 & 0,439 & 0,355 & 2,077 & 1,447 \\
\hline
\end{tabular}

Fuente: SPSS, versión 22

Cuadro. 8. ANOVA del modelo

\begin{tabular}{|l|l|c|c|c|c|c|}
\hline \multicolumn{2}{|c|}{ Modelo } & $\begin{array}{c}\text { Suma de } \\
\text { cuadrados }\end{array}$ & gl & $\begin{array}{c}\text { Media } \\
\text { cuadrática }\end{array}$ & F & Sig. \\
\hline \multirow{2}{*}{1} & Regresión & 67,659 & 3 & 22,553 & 5,227 & 0,008 \\
\cline { 2 - 7 } & Residuo & 86,300 & 20 & 4,315 & $-\ldots-$ - & $-\ldots$ \\
\cline { 2 - 7 } & Total & 153,958 & 23 & $-\ldots-\ldots$ & $-\ldots$ & $-\ldots$ \\
\hline
\end{tabular}

Fuente: SPSS, versión 22

El Cuadro 7 recoge la información sobre el resumen del modelo de regresión propuesto, donde se observa que el valor de $\mathrm{R}^{2}$ es de 0,439 , lo que indica que los regresores explican de manera conjunta un $44 \%$ de la varianza de la variable endógena, por lo que el ajuste puede calificarse de relativamente satisfactorio, justificando además el nivel de significación (Sig. $=0,008$ ) del ANOVA incluida en el Cuadro 8 que es nula la probabilidad de que el conjunto de regresores incluidos en el modelo no sea suficiente para predecir los valores de la variable dependiente.

Además, el estadístico de Durbin-Watson informa sobre el grado de independencia de los residuos respecto de las variables explicativas y la variable endógena, aceptándose que los residuos cumplen la condición de independencia cuando dicho estadístico se sitúa entre 1,5 y 2,5, (Fuente Fernández, 2011), por lo que teniendo en cuenta que en nuestro caso toma el valor de 1,447, se asume dicha independencia.

El modelo de regresión estimado se recoge en el Cuadro 9:

Cuadro. 9. Resultado del modelo de regresión lineal

\begin{tabular}{|c|c|c|c|c|c|c|c|c|c|}
\hline \multirow{2}{*}{ Modelo } & \multicolumn{2}{|c|}{$\begin{array}{l}\text { Coeficientes no } \\
\text { estandarizados }\end{array}$} & \multirow{2}{*}{$\begin{array}{c}\begin{array}{c}\text { Coeficientes } \\
\text { estandarizados }\end{array} \\
\text { Beta }\end{array}$} & \multirow{2}{*}{$\mathbf{t}$} & \multirow{2}{*}{ Sig. } & \multirow{2}{*}{ VIF } & \multicolumn{3}{|c|}{ Correlaciones } \\
\hline & B & $\begin{array}{c}\text { Error } \\
\text { estándar }\end{array}$ & & & & & Cero & Parcial & Semiparcial \\
\hline (Constante) & $-4,196$ & 3,460 & $-\ldots$ & $-1,212$ & 0,239 & - . - & $\ldots$ & $-\ldots$ & - - - \\
\hline $\mathbf{S}_{1}$ & 4,295 & 2,513 & 0,346 & 1,709 & 0,103 & 1,465 & 0,521 & 0,357 & 0,286 \\
\hline $\mathbf{S}_{3}$ & 2,475 & 1,580 & 0,317 & 1,566 & 0,133 & 1,466 & 0,520 & 0,331 & 0,262 \\
\hline $\mathbf{S}_{5}$ & 8,253 & 4,530 & 0,305 & 1,822 & 0,083 & 1,002 & 0,308 & 0,377 & 0,305 \\
\hline
\end{tabular}

Fuente: SPSS, versión 22

Una vez obtenidos los resultados del modelo, un aspecto importante es conocer si los residuos o errores de la predicción son homocedásticos, es decir, se debe comprobar si la variación de los residuos es uniforme y no existen pautas de asociación (varianza constante), a cuyo fin se aplicó el test de Breusch-Pagan, cuya hipótesis nula acepta la existencia de homocedasticidad, en contra de la presencia de heterocedasticidad. Los resultados del citado test $(\mathrm{Chi} 2=0,20 ; \mathrm{p} \text {-value }=0,888)^{7}$ no permiten rechazar la hipótesis nula, por lo que se acepta que los residuos del modelo son homocedásticos. Además, entre los resultados del modelo se incluyó el "factor de inflación de la varianza" (variance inflation factor, VIF), que detecta la presencia de multicolinealidad cuando alcanza valores superiores a 10 , por lo que se confirma la ausencia de dicha 
característica dado que para todos los regresores los resultados del VIF están en parámetros en torno a la horquilla 1 a 1,5 .

Dando por cumplidos los supuestos de normalidad (test Shapiro-Wilk) y ausencia de multicolinealidad (VIF) de las variables explicativas, así como la independencia (test Durbin-Watson) y homocedasticidad (test Breusch-Pagan) de los residuos, los resultados del modelo de regresión evidencian una relación positiva y significativa al $10 \%$ de la variable explicativa $\left(\mathrm{S}_{5}\right)$, lo que permite afirmar con cierta cautela que un incremento de una unidad en el nivel organizativo referido a la funcionalidad de la web del partido político incrementaría la transparencia económica en 8,253 unidades, manteniéndose constantes el resto de variables predictoras, que de acuerdo a su nivel de significación no permiten realizar otro tipo de aseveraciones.

A fin de conocer con mayor detalle el efecto de los regresores del modelo sobre la variable endógena, se calcularon adicionalmente los coeficientes de correlación "cero", "parcial y "semiparcial". La correlación "cero" mide el efecto entre la variable endógena y cada uno de los regresores sin considerar la presencia del resto, determinando la correlación "parcial" el grado de relación de cada variable explicativa sobre la variable endógena eliminando el efecto del resto de variables incluidas en el modelo, mientras que la correlación "semiparcial" evalúa el grado de relación que existe entre la variable explicada y los regresores, pero eliminando para cada regresor el efecto de los restantes. En este sentido, se observa que de los tres regresores incluidos en el modelo, solamente la variable $\left(S_{5}\right)$ mantiene o incrementa la correlación con la variable endógena cuando se eliminan los efectos del resto de variables del modelo (correlación "cero" = 0,308 vs. correlación "parcial" $=0,377$ ) o únicamente los correspondientes al resto de regresores (correlación "cero" $=0,308$ vs. correlación "semiparcial" $=0,305)$, lo que confirma la importancia de dicha variable explicativa dentro del modelo diseñado.

\section{Conclusiones}

La entrada en vigor de la Ley de Transparencia (Ley 19/2013) ha venido a configurar un nuevo foco de atención sobre las actividades de los organismos públicos, por cuanto obliga a dichos entes a facilitar a los ciudadanos la información necesaria para poder enjuiciar sus actuaciones, hecho que adquiere aún mayor importancia si se tiene en cuenta que, como menciona la propia ley, "los países con mayores niveles en materia de transparencia y normas de buen gobierno cuentan con instituciones más fuertes, que favorecen el crecimiento económico y el desarrollo social".

La Ley de Transparencia recoge un amplio ámbito de actuación, dentro del que se encuentran las formaciones políticas, sobre cuya actuación se han venido aprobando a lo largo de los años distintas leyes con el objetivo de dotar de un marco teórico al concepto de transparencia, en aras de poner a disposición de la ciudadanía en general cualquier información que sea requerida. Sin embargo, el conjunto de leyes aludido se muestra excesivamente escueto y general, no profundizando ni aclarando cuáles deben ser exactamente los requisitos que una formación política tiene que cumplir para poder ser calificada de transparente. En este aspecto, las investigaciones llevadas a cabo por diversas organizaciones han tenido por objeto aclarar y establecer una hoja de ruta clara en materia de transparencia ante las insuficiencias mostradas por la legislación promulgada, y en ese sentido, el presente estudio intenta recoger el testigo de dichas organizaciones, con el fin de profundizar en el análisis de las webs, partiendo de la premisa de la generalización del uso de dicho medio por parte de prácticamente la totalidad de las formaciones políticas.

Tras el análisis estadístico y econométrico realizado es posible afirmar que las formaciones políticas españolas pueden clasificarse en diversas categorías de acuerdo a los diferentes niveles de información que publican, revelando una filosofía compartida en cuanto a la forma y fondo en el uso de las páginas web por el conjunto de las entidades clasificadas dentro de una misma categoría.

Además, también se constata que los partidos políticos incluidos en el estudio ofrecen una información alejada del nivel medio que podría ser aceptable en materia de transparencia, tanto desde el punto de vista organizativo como económico, tal como se puede comprobar al examinar los resultados de los respectivos índices elaborados $a d$ hoc, si bien con la excepción de un pequeño grupo (calificados en el estudio como "más transparentes"), que presentan un mayor volumen de información respecto del resto. Asimismo, se debe destacar que la información que publican dichos entes relacionada con la organización es mayor que la concerniente a sus aspectos económicos.

En cuanto a la existencia de una posible relación de causalidad entre los índices de transparencia evaluados, del análisis econométrico practicado se desprende que los subíndices de transparencia organizativa explican en su conjunto las variaciones de la transparencia económica, pudiendo afirmarse de forma más concreta que mayores niveles de funcionalidad de la web del partido político posibilitarían incrementos en la información relativa a la transparencia económica, si bien esta apreciación debe considerarse con cautela de acuerdo al nivel de significación del coeficiente asociado a dicha variable.

En síntesis podemos concluir que, aunque las formaciones políticas se están sumando a la utilización de la herramienta web para fomentar su transparencia, aún queda un largo camino que recorrer, debiendo tomarse 
un mayor nivel de conciencia respecto a la generalización del uso de este medio, y el papel vital que desarrolla en una sociedad tecnológica como la que vivimos hoy en día. En este punto cabe destacar el trabajo que han venido realizando determinadas formaciones políticas en materia de transparencia, que debería ser el hilo conductor para aquellas que todavía presentan déficit en este temática, pues a tenor de los resultados sobre los aspectos contemplados en los diferentes índices de transparencia, sería preciso un mayor esfuerzo por parte de los partidos políticos para cubrir estos espacios de información altamente demandados, lo que implicaría a su vez una mayor atención por parte del legislador para delimitar de forma más explícita los hitos que las formaciones políticas deben cumplir con el fin de alcanzar un nivel de transparencia adecuado, y que los mismos puedan ser revisables en función de las cambiantes y nuevas demandas informativas de la sociedad.

Como futuras líneas de investigación sobre la temática tratada, sería interesante abordar un análisis en cuanto a la calidad y cantidad de la información proporcionada por las formaciones políticas, así como de los diferentes índices de medida de la transparencia desde un punto de vista comparativo.

\section{Referencias bibliográficas}

Acess Info (2019) España, cinco años de Ley de Transparencia. Disponible en: https://www.accessinfo.org/es/blog/2019/12/10/espana-cinco-anos-de-la-ley-de-transparencia/ (07/06/2020).

Anova Irmandade Nacionalista (2020) Página web oficial. Disponible en: https://www.anova.gal/ (16/03/2020).

Arredondo Trapero, F.G.; de la Garza García, J.; Vázquez Parra J. C. (2014) Transparencia en las organizaciones, una aproximación desde la perspectiva de los colaboradores. Estudios Gerenciales, Vol. 30, N ${ }^{\circ}$ 133. Disponible en: https://reader.elsevier.com/reader/sd/pii/S0123592314001569?token=06B152351E5C4081FAE396E6CCC2934BD 773C7BFE4AF26909C4A9F4742358C2D5D61374601EF697B41C436C436DFBA82\&originRegion=eu-west1\&originCreation $=20210416105432(12 / 03 / 2020)$.

Ball, C. (2009) What Is Transparency?. Public Integrity, 11 (4), 293-308. DOI: 10.2753/PIN1099-9922110400. Disponible en: https://www.researchgate.net/publication/250174526 What Is Transparency (12/03/2020).

Barcelona en Comú Podem (2020) Página web oficial. Disponible en: https://barcelonaencomu.cat/ (17/03/2020).

Cárdenas, J. (2014) Qué es la Regresión Lineal Múltiple y cómo analizarla en 4 pasos. Networkianos. Blog de Sociología. Disponible en: http://networkianos.com/regresion-lineal-multiple/ (03/05/2020).

Cavaller, V. (2017) Información asimétrica. 2017. Revista dels Estudis de Ciènces de la Informació $i$ de la Comunicació, $\mathrm{N}^{\circ}$ 64. Disponible en: https://comein.uoc.edu/divulgacio/comein/es/numero64/articles/informacionasimetrica.html (02/04/2020).

Catalunya en Comú (2020) Página web oficial. Disponible en: https://catalunyaencomu.cat/ (18/03/2020).

Cavanna, J. (2014) Los 7 grandes errores de la nueva Ley de Transparencia. Revista compromiso empresarial. Disponible en: https://www.compromisoempresarial.com/opinion/2014/01/los-7-grandes-errores-de-la-nueva-leyde-transparencia/ (13/03/2020).

Ciudadanos-Partido de la ciudadanía (2020) Página web oficial. Disponible en: https://www.ciudadanos-cs.org/ $(19 / 03 / 2020)$.

Christensen, L. T.; Cheney, G. (2015) Peering into Transparency: Challenging Ideals, Proxies, and Organizational Practices. Communication Theory, 25 (1), pp. 70-90. Disponible en: http://doi.org/10.1111/comt.12052 $(12 / 03 / 2020)$.

Coalició Compromís: Bloc Iniciativa Verds (2020) Página web oficial. Disponible en: https://compromis.net/ $(20 / 03 / 2020)$.

Coalición Canaria (2020) Página web oficial. Disponible en: http://coalicioncanaria.org/ (21/03/2020).

Convergència Democràtica de Catalunya (2020) Página web oficial. Disponible en: https://web.archive.org/web/20160614225752/http://www.convergencia.cat/ (22/03/2020).

Dader, J. L.; Campos, E.; Quintana, N. (2011) Las webs de los partidos en la campaña de 2011: Una panorámica cualitativa de su actividad y un análisis cuantitativo de su transparencia, en Crespo, I. (coord.). Partidos, medios y electores en proceso de cambio: las Elecciones Generales Españolas de 2011, pp. 239-274. Valencia: Tirant lo Blanch. Disponible en:

https://www.researchgate.net/publication/270390696_Las_webs_de_los_partidos_en_la_campana_de_2011_Una_p anoramica_cualitativa_de_su_actividad_y_un_analisis_cuantitativo_de_su_transparencia (12/03/2020).

De Lorenzo, R. (2017) Las obligaciones derivadas de la Ley de Transparencia. Redacción Médica. Disponible en: https://www.redaccionmedica.com/opinion/las-obligaciones-derivadas-de-la-ley-de-transparencia-3254 $(13 / 03 / 2020)$.

Del Campo Moreno, P.; Herrador Alcaide, T.C.; Segovia San Juan, A.I. (2016) La transparencia organizativa y económica en la web de las fundaciones: un estudio empírico para España. REVESCO, Revista de Estudios

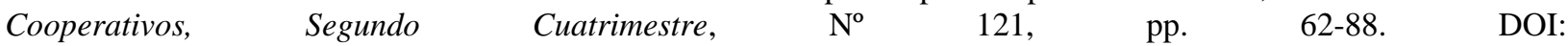
http://dx.doi.org/10.5209/rev_REVE.2016.v121.49701.

Díez Garrido, M.; Campos Domínguez, E.; Calvo, D. (2019) La transparencia de los partidos como estrategia electoral. Una evaluación de sus promesas y sus páginas web, Trípodos, 44, 83-104. Disponible en: http://www.tripodos.com/index.php/Facultat_Comunicacio_Blanquerna/article/view/620 (13/03/2020). 
Equo (2020) Página web oficial. Disponible en: https://partidoequo.es/ (23/03/2020).

Esquerra Republicana de Catalunya (2020) Página web oficial. Disponible en: https://www.esquerra.cat/ca/inici (24/03/2020).

Esquerra Unida del País Valencià (2020) Página web oficial. Disponible en: http://eupv.org/ (25/03/2020).

Esquerra Unida i Alternativa (2020) Página web oficial. Disponible en: https://www.semprealesquerra.cat/ $(26 / 03 / 2020)$.

Eusko Alderdi Jetlzalea - Partido Nacionalista Vasco (2020) Página web oficial. Disponible en: https://www.eajpnv.eus/ (27/03/2020).

Euskal Herria Bildu (2020) Página web oficial. Disponible en: https://ehbildu.eus/es (28/03/2020).

Expansión (2018) Índice de percepción de la corrupción. Organización Transparencia Internacional. Disponible en: https://datosmacro.expansion.com/estado/indice-percepcion-corrupcion (20/03/2020).

Foro de Ciudadanos (2020) Página web oficial. Disponible en: https://www.foroasturias.es/ (29/03/2020).

Fuente Fernández, S. (2011) Regresión múltiple. Facultad de Ciencias Económicas y Empresariales. Universidad Autónoma de Madrid.

Fundación Ciudadana Civio (2019) Insistimos por cuarta vez: el reglamento de la Ley de Transparencia no puede restar derechos. Disponible en: https://civio.es/novedades/2019/03/25/insistimos-por-cuarta-vez-el-reglamento-dela-ley-de-transparencia-no-puede-restar-derechos/ (12/03/2020).

Fundación Compromiso y Transparencia (2017) Rankings de transparencia. Disponible en: https://www.compromisoytransparencia.com/rankings-de-transparencia/sector/partidos-politicos (08/06/2020).

Gavilanes, M.A.; Andrés A. (2016) ¿Cómo se financian los partidos políticos? Disponible en: https://civio.es/el-boenuestro-de-cada-dia/2016/11/14/como-se-financian-los-partidos-politicos/ (25/02/2020).

Harrison, T.; Sayogo, D. (2014) Transparency, participation, and accountability practices in open government: A comparative study. Government Information Quarterly, No 31, pp. 513-525. DOI: 10.1016/j.giq.2014.08.002 $(03 / 06 / 2020)$.

Hermosa del Vasto, P.; Alcaraz Quiles F.J.; Urquía Grande, E. (2017) Transparencia pública y rendición de cuentas como base para la construcción de una sociedad democrática en América Latina. Revista Internacional Transparencia e Integridad, 4, mayo - agosto. Disponible en: https://revistainternacionaltransparencia.org/wpcontent/uploads/2017/08/9.-Paola-Hermosa-y-otros.pdf (12/03/2020).

Hollyer, J.R.; Rosendorff, B.P.; Vreeland, J.R. (2011) Democracy and Transparency. The Journal of Politics, 73(4), pp. 1191-1205. Disponible en: https://doi.org/10.1017/S0022381611000880 (12/03/2020).

Instituto Nacional de Tecnologías Educativas y Formación del Profesorado (2020) Concepto de Web 2.0. Disponible en: http://www.ite.educacion.es/formacion/materiales/155/cd/modulo_1_Iniciacionblog/concepto_de_web_20.html $(23 / 04 / 2020)$.

Izquierda Unida (2020) Página web oficial. Disponible en: https://izquierdaunida.org/ (30/03/2020).

Larrondo Ureta, A. (2016) Comunicación organizacional ante el reto de la estrategia multiplataforma y 2.0: la experiencia de los partidos políticos en el País Vasco. El Profesional de la Información, 25 (1), pp. 114-123. Disponible en: http://doi.org/10.3145/epi.2016.ene.11 (13/03/2020).

Ley 19/2013 de transparencia, acceso a la información pública y buen gobierno.

Ley Orgánica 6/2002, de 27 de junio, de Partidos Políticos.

Ley Orgánica 8/2007, de 4 de julio, sobre financiación de los Partidos Políticos.

Ley Orgánica 5/2012, de 22 de octubre, de reforma de la Ley Orgánica 8/2007, de 4 de julio, sobre financiación de los Partidos Políticos.

Ley Orgánica 3/2015, de 30 de marzo, de control de la actividad económico-financiera de los Partidos Políticos, por la que se modifican la Ley Orgánica 8/2007, de 4 de julio, sobre financiación de los Partidos Políticos, Ley Orgánica 6/2002, de 27 de junio, de Partidos Políticos y la Ley Orgánica 2/1982, de 12 de mayo, del Tribunal de Cuentas.

Martín Q.; Cabrero Morán M.T.; De Paz Santana Y. (2008) Tratamiento estadístico de datos con SPSS: Prácticas resueltas $y \quad$ comentadas. ISBN: 978-84-9732-553-0, 56-57. Disponible en: https://books.google.es/books?id=p2kswpzT2oEC\&printsec=frontcover\&dq=tratamiento+estadistico+de+datos+con + spss\&hl=es\&sa=X\&ved=0ahUKEwi $40 u \_2 s 7$ pAhUPD2MBHSDjBMQ6AEIKDAA\#v=onepage\&q=tratamiento $\% 20$ estadistico $\% 20 \mathrm{de} \% 20$ datos $\% 20$ con $\% 20$ spss \&f=false (20/04/2020).

Martisi, B. (2016) Ningún partido político es transparente según el ranking de Compromiso y Transparencia. Revista Compromiso Empresarial. Disponible en: https://www.compromisoempresarial.com/transparencia/2016/06/ningunpartido-politico-es-transparente-segun-el-ranking-de-fundacion-compromiso-y-transparencia/ (03/06/2020).

Más País (2020) Página web oficial. Disponible en: https://maspais.es/ (31/03/2020).

Morales A.M.; Martínez, S.; García, F.; Caridad, M. (2016) La transparencia en la política española: análisis de su influencia y presencia en los medios sociales. Ibersid, Revista de sistemas de información y documentación, $\mathrm{N}^{\mathrm{o}} 2$, pp. 91-96. Disponible en: https://www.ibersid.eu/ojs/index.php/ibersid/article/view/4350 (28/03/2020).

Nueva Canarias - Nueva Gran Canaria (2020) Página web oficial. Disponible en: https://nuevacanariaslpgc.org/ $(01 / 04 / 2020)$.

Oxford University Press (2020) Definición de transparencia. Disponible en: https://www.lexico.com/es/definicion/transparencia (16/02/2020).

Partido Aragonés (2020) Página web oficial. Disponible en: http://www.partidoaragones.es/ (02/04/2020). 
Partido Popular (2020) Página web oficial. Disponible en: http://www.pp.es/ (03/04/2020).

Partido Regionalista de Cantabria (2020) Página web oficial. Disponible en: http://prc.es/ (04/04/2020).

Partido Socialista Obrero Español (2020) Página web oficial. Disponible en: https://www.psoe.es/ (05/04/2020).

Partit dels Socialistes de Catalunya (2020) Página web oficial. Disponible en: http://www.socialistes.cat/ (06/04/2020).

Partit Demòcrata Europeu Català (2020) Página web oficial. Disponible en: https://www.partitdemocrata.cat/ $(07 / 04 / 2020)$.

Podemos (2020) Página web oficial. Disponible en: https://podemos.info/ (08/04/2020).

Por un mundo más justo (M+J) (2019) La transparencia en los partidos políticos: la mejor herramienta para prevenir la corrupción. Disponible en: https://www.porunmundomasjusto.es/la-transparencia-en-los-partidos-politicos-lamejor-herramienta-para-prevenir-la-corrupcion/ (16/03/2020).

Rodríguez López, Á. (2011) Contabilidad y Financiación de los Partidos Políticos. Editorial CISS, Madrid.

Rodríguez López, A. (2012) Análisis de las modalidades de financiación pública directa de los partidos políticos. Actualidad administrativa, $\mathrm{N}^{\mathrm{0}} 21,4$.

Rodríguez López, A. (2014) Los recursos financieros privados internos en el ámbito de la política. Actualidad $\begin{array}{lllll}\text { Administrativa } & \text { (La } & \text { Ley), } & 490-496 . & \text { Disponible }\end{array}$ https://www.researchgate.net/publication/311740168_Los_recursos_financieros_privados_internos_en_el_ambito_d e la_politica $(12 / 11 / 2020)$.

Rodríguez López, A. (2018) Reflexiones acerca de la contabilidad y financiación irregular de partidos políticos. Actualidad Administrativa, $\mathrm{N}^{\circ}$ 2, pp. 1-7.

Rodríguez López, A.; Fidalgo Cerviño, E. (2010) Transparencia y credibilidad: El caso de los partidos políticos en España, Partida Doble, No 218, pp. 18-24. Disponible en: http://pdfs.wke.es/7/0/8/8/pd0000047088.pdf $(12 / 11 / 2020)$.

Rodríguez López, Á.; Fidalgo Cerviño, E. (2011) Control financiero, rendición de cuentas y códigos de buen gobierno en el entorno político español. Revista de Contabilidad y Tributación, № 337, pp. 137-160.

Rodríguez López, Á.; Fidalgo Cerviño, E. (2012) Responsabilidad social, crisis financiera y normalización contable en los partidos políticos españoles. CIRIEC-España, Revista de Economía Pública, Social y Cooperativa, $\mathrm{N}^{\mathrm{0}} 74, \mathrm{pp}$. 239-260.

Sevillano, E.; De Barrón, I. (2019) Así se financian los partidos políticos: el $80 \%$ es dinero público. Disponible en: https://elpais.com/politica/2019/03/22/actualidad/1553285034 275739.html (25/02/2020).

Sobiranistes (2020) Página web oficial. Disponible en: https://www.sobiranistes.cat/ (09/04/2020).

Transparencia Castilla - La Mancha (2020) ¿Qué es y para qué sirve la transparencia? Disponible en: https://transparencia.castillalamancha.es/transparencia (03/03/2020).

Teruel Existe (2020) Página web oficial. Disponible en: https://teruelexiste.info/ (10/04/2020).

Transparencia Internacional España (2017) Evaluación del nivel de transparencia de los partidos políticos 2017. Disponible en: https://transparencia.org.es/evaluacion-del-nivel-de-transparencia-de-los-partidos-politicos-2017/ $(12 / 03 / 2020)$.

Unión del Pueblo Navarro (2020) Página web oficial. Disponible en: https://www.upn.org/ (11/04/2020).

Unión, Progreso y Democracia (2020) Página web oficial. Disponible en: https://www.upyd.es/ (12/04/2020).

VOX (2020) Página web oficial. Disponible en: https://www.voxespana.es/ (13/04/2020). 
Apéndice. 1. Índice de Transparencia Organizativa (ITO) de los partidos políticos

\begin{tabular}{|c|c|}
\hline Subíndices (con desglose por ítems) & Puntaciones \\
\hline S1. Información sobre el partido político & $\mathbf{1 , 0 0}$ \\
\hline $\mathbf{S}_{1.1 .}$ Historia de la formación & 0,143 \\
\hline S1.2. Declaración de principios, valores y fines del partido & 0,143 \\
\hline $\mathbf{S}_{1.3 .}$ Organigrama del partido & 0,143 \\
\hline S1.4. Comunidades autónomas y provincias en las que está constituido el partido & 0,143 \\
\hline $\begin{array}{l}\text { S1.5. Publicación de la dirección de las oficinas o sedes del partido (al menos a } \\
\text { nivel provincial), y sus respectivos datos de contacto }\end{array}$ & 0,143 \\
\hline S1.6. Agenda de las actividades públicas previstas por el partido & 0,143 \\
\hline S1.7. Descripción del sistema de control y/o auditoría interna del partido & 0,143 \\
\hline$S_{2 .}$ Información sobre máximos cargos e integrantes del partido político & 1,00 \\
\hline $\mathbf{S}_{2.1 .}$ Agenda del presidente/secretario general & 0,125 \\
\hline $\begin{array}{l}\text { S2.2. Currículum o datos biográficos (más de cinco líneas) de los miembros de los } \\
\text { máximos órganos ejecutivos del partido }\end{array}$ & 0,125 \\
\hline $\mathbf{S}_{2.3 .}$ Descripción de los procedimientos de elección de los cargos del partido & 0,125 \\
\hline $\mathbf{S}_{2.4 .}$ Publicación de los acuerdos de los máximos órganos del partido & 0,125 \\
\hline $\begin{array}{l}\text { S2.5. Currículum o datos biográficos (más de cinco líneas) de los principales } \\
\text { candidatos incluidos en las últimas listas electorales }\end{array}$ & 0,125 \\
\hline $\begin{array}{l}\text { S2.6. Información y requisitos sobre el nombramiento de las personas responsables } \\
\text { de la gestión económico-financiera }\end{array}$ & 0,125 \\
\hline $\begin{array}{l}\text { S2.7. Remuneraciones brutas (anuales o medias) de los distintos órganos ejecutivos } \\
\text { del partido }\end{array}$ & 0,125 \\
\hline $\begin{array}{l}\text { S2.8. Declaración expresa de la inexistencia de procesados por corrupción en las } \\
\text { listas electorales }\end{array}$ & 0,125 \\
\hline S3. Información sobre entidades vinculadas, afiliados y ciudadanía & $\mathbf{1 , 0 0}$ \\
\hline $\begin{array}{l}\text { S3.1. Descripción, ubicación y datos de contacto de las entidades vinculadas al } \\
\text { partido }\end{array}$ & 0,20 \\
\hline S3.2. Cuentas anuales completas de las entidades vinculadas al partido & 0,20 \\
\hline S3.3. Publicación del número de afiliados del partido & 0,20 \\
\hline S3.4. Publicación de los requisitos y procedimientos para afiliarse al partido & 0,20 \\
\hline S3.5. Canales o sistemas específicos de denuncia para afiliados o ciudadanos & 0,20 \\
\hline S4. Comunicación pública en la web del partido & $\mathbf{1 , 0 0}$ \\
\hline S4.1. Es posible identificar en la homepage la palabra "transparencia" & 0,083 \\
\hline $\begin{array}{l}\text { S.2. La web tiene un espacio dedicado únicamente a la transparencia: Portal de } \\
\text { Transparencia }\end{array}$ & 0,083 \\
\hline $\begin{array}{l}\text { S4.3. La información dentro del portal de transparencia está estructurada de manera } \\
\text { clara y ordenada }\end{array}$ & 0,083 \\
\hline $\begin{array}{l}\text { S4.4. Dentro del portal de transparencia aparece información relativa a, al menos, } \\
\text { tres ejercicios económicos }\end{array}$ & 0,083 \\
\hline $\begin{array}{l}\text { S4.5. Se puede visualizar dentro del portal se transparencia información } \\
\text { cuantitativa referente a las dos últimas campañas electorales: subvenciones } \\
\text { recibidas, órganos de concesión de estas etc. }\end{array}$ & 0,083 \\
\hline $\begin{array}{l}\text { S.6. La página web muestra las fechas y horas en las que se ha publicado } \\
\text { cualquier tipo de información }\end{array}$ & 0,083 \\
\hline $\begin{array}{l}\text { S.7. La página web dispone de un espacio para realizar donaciones en la que } \\
\text { explica la normativa referente a las mismas }\end{array}$ & 0,083 \\
\hline S4.8. La página web permite acceder/descargarse los estatutos del partido & 0,083 \\
\hline $\begin{array}{l}\text { S4.9. La página web tiene establecidos métodos para poder contactar con el } \\
\text { partido: teléfono, mail, formularios, dirección física, encuestas etc. }\end{array}$ & 0,083 \\
\hline $\begin{array}{l}\text { S.10. La página web dispone de un foro de participación o un apartado de } \\
\text { sugerencias para hacer partícipes a los ciudadanos }\end{array}$ & 0,083 \\
\hline S4.11. La página web dispone de un mecanismo para poder afiliarse al partido & 0,083 \\
\hline $\mathbf{S}_{\text {4.12. La página web dispone de un espacio únicamente habilitado para militantes }}$ & 0,083 \\
\hline S5. Funcionalidad del sitio web del partido político & 1,00 \\
\hline $\begin{array}{l}\text { S5.1. La página web del partido es fácilmente identificable (logotipo o eslogan en } \\
\text { la parte superior del sitio web) }\end{array}$ & 0,09 \\
\hline
\end{tabular}


Apéndice. 1. Índice de Transparencia Organizativa (ITO) de los partidos políticos

\begin{tabular}{|l|c|}
\hline \multicolumn{1}{|c|}{ Subíndices (con desglose por ítems) } & Puntaciones \\
\hline S5.2. El tiempo de carga de la página web es adecuado (inferior a 2 segundos) & 0,09 \\
\hline S5.3. La web está disponible en la lengua oficial del país (castellano) & 0,09 \\
\hline $\begin{array}{l}\text { S5.4. La web se encuentra disponible en otras lenguas oficiales de España (catalán, } \\
\text { euskera, gallego) }\end{array}$ & 0,09 \\
\hline S5.5. El icono principal de la web permite volver a la homepage & 0,09 \\
\hline $\begin{array}{l}\text { S5.6. Dentro de la página web hay buscadores para hacer más fácil y concisa la } \\
\text { navegación }\end{array}$ & 0,09 \\
\hline S5.7. La página web dispone de accesos directos a sus redes sociales & 0,09 \\
\hline $\begin{array}{l}\text { S5.8. La página web dispone de herramientas para visualizar redes sociales de } \\
\text { acción inmediata (Twitter, Facebook, etc...) }\end{array}$ & 0,09 \\
\hline $\begin{array}{l}\text { S5.9. La página web es accesible desde todas las plataformas (ordenador, móvil y/o } \\
\text { tablet) }\end{array}$ & 0,09 \\
\hline S5.10. El partido dispone de una App gratuita para smartphone y tablet & 0,09 \\
\hline S5.11. En la página web se hace alusión a la App del partido & 0,09 \\
\hline TOTAL INDICE TRANSPARENCIA ORGANIZATIVA (ITO) & $\mathbf{5 , 0 0}$ \\
\hline
\end{tabular}

Fuente: Elaboración propia 
Apéndice 2. Índice de Transparencia Económica (ITE) de los partidos políticos

\begin{tabular}{|l|c|}
\hline \multicolumn{1}{|c|}{ Ítems } & Puntuaciones \\
\hline $\begin{array}{l}\text { I. } \text { Cuentas anuales del partido (Balance, Cuenta de resultados y Memoria) } \\
\text { consolidadas a nivel estatal, autonómico y provincial de los últimos dos } \\
\text { ejercicios económicos }\end{array}$ & 1,00 \\
\hline $\begin{array}{l}\text { I. Fechas en las que el partido ha remitido sus cuentas al Tribunal de Cuentas en } \\
\text { los dos últimos ejercicios }\end{array}$ & 1,00 \\
\hline $\begin{array}{l}\text { I3. Últimos informes de fiscalización de cuentas del partido emitidos por el } \\
\text { Tribunal de Cuentas }\end{array}$ & 1,00 \\
\hline I4. Presupuestos anuales del partido de los últimos dos ejercicios & 1,00 \\
\hline I5. Desglose de los gastos e ingresos a nivel estatal, autonómico y provincial & 1,00 \\
\hline $\begin{array}{l}\text { I6. Información económica, presupuestaria y estadística relativa a convenios y } \\
\text { contratos }\end{array}$ & 1,00 \\
\hline I7. Información detallada de los bienes que están en posesión del partido & 1,00 \\
\hline I8. Información detallada de las subvenciones públicas recibidas & 1,00 \\
\hline I9. Información detallada de las donaciones recibidas (en dinero y en especie) & 1,00 \\
\hline $\begin{array}{l}\text { I10. Detalle de los gastos electorales de las últimas elecciones, y límites legalmente } \\
\text { establecidos para estos gastos }\end{array}$ & 1,00 \\
\hline $\begin{array}{l}\text { I11. Información detallada sobre los préstamos y créditos pendientes de } \\
\text { amortización (entidad que lo concede, importe concedido, tipo de interés y } \\
\text { plazo de amortización) }\end{array}$ & 1,00 \\
\hline TOTAL INDICE TRANSPARENCIA ECONÓMICA (ITE) & $\mathbf{1 1 , 0}$ \\
\hline
\end{tabular}

Fuente: Elaboración propia 